\title{
NUMERICAL SIMULATION OF AN AGRICULTURAL SOIL SHEAR STRESS TEST
}

\author{
Andrea Formato, Salvatore Faugno
}

\section{Introduction}

A better understanding of stressed soil strain could significantly improve the design of working tools and lead to more efficient and effective performance. Furthermore, it is very important for understanding the mechanical characteristics of soil including soil shear strength [9], [13], [16], [22]. The shear strength of a soil is required in order to address several problems such as the resistance to traction and tillage tools for agriculture engineering applications. Over the past years, several shear stress "in situ" measurement techniques have already been used to measure soil shear strength [14], [21], [26]. During the "in situ" measurement tests, the soil shear stress is determined by a special device known as a soil shearometer. However, measurement techniques used in the past were rather complicated, time-consuming and difficult to apply to large-scale measurement [26]. Furthermore, relationships between various shear resistance measurement techniques were not readily available and the data collected using different methods was not easily comparable. Nowadays, user friendly equipment is available, and one of these tools produced by Eijkelkamp enabled us to obtain the shear stress value for a specific soil more easily [4], [12].

Another problem posed by agricultural soil mechanics is that of determining the mechanical behaviour of the considered soil during the shear test. This has been studied by numerous authors through numerical simulation of the considered test [6], [8], [19], [24]. They hypothesized a type of mechanical behaviour for the considered soil and afterwards calculated the values of the local stresses and strains through numerical simulation. By making comparisons between the data results obtained through numerical simulation

Paper present 2.04.2006; accepted 13.02.2007

Andrea Formato, Researcher, Salvatore Faugno, Researcher, Department of Agricultural Engineering and Agronomy, University of Naples "Federico II". Italy. E-mail: formato@unina.it Research has been coordinated by Formato. Both authors have performed the tests, discussed the data results and written the paper. and experimental tests, they identified the material model that simulated the considered soil extremely well. Nowadays, powerful FEM computational codes are "easily" available with a very rich library of material models plus very elaborate and sophisticated constitutive laws that allow the simulation of complicated experimental tests from an analytical and geometric point of view to be performed.

The numerical simulation of the agricultural soil shear tests was addressed in this way in this paper. The experimental tests were carried out using simplified equipment available on the market and aimed to determine the mechanical behaviour model of the considered soil. The "set" of material models to be examined was chosen from the models broadly used and "tested" by different authors for typologies of soils similar to those considered in this paper and specifically the material models of Mohr Coulomb, Drucker Prager and Cam Clay [1].

\section{Materials and methods}

Our research concerns the numerical modelling of 5 different soil types located on the right side of the Sele river, at a distance of about $1 \mathrm{~km}$ from each other along the perpendicular to the Sele river towards the sea. Material numerical models of the considered soils were evaluated by comparing soil shear tests with numerical simulation data results obtained using three material models frequently used in soil literature, the Mohr Coulomb, Drucker-Prager and Cam Clay models. Furthermore, we had to pre-determine soil parameter values obtained by soil tests on soil samples to carry out this research. For this purpose, soil samples were taken from 5 different soil parcels considered. We collected 4 soil samples for each soil type considered by following a regular square grid $5 \mathrm{~m}$ long on each side and also evaluated the soil moisture content for each soil.

Apparent soil-metal friction coefficient was evaluated by a simple slider system at four levels of normal stress: $0.70,1.10,1.50$ and $2.30 \mathrm{kPa}$. We then considered the average value obtained from these tests. 
To perform the shear test numerical simulations, we used the FEM program code, Abaqus. It is a powerful program code that is broadly used to perform "non linear" analysis. It also has a very rich library of "non linear" material models and was able to simulate different soil typologies [1].

We detected other parameters needed to perform soil shear test numerical simulation by using the Abaqus program code. They were obtained with hydrostatic compression tests [2], [10], [15], and triaxial tests [3], [7], [11], [25], performed on considered soil samples, and more specifically, texture analysis with the percentage of clay, silt and sand; upper and lower Atterberg Parameters, APLU, APLL $\left(\% \mathrm{H}_{2} \mathrm{O}\right)$; moisture $m$ (moisture content / total mass: $\mathrm{kg} / \mathrm{kg} \%$ ); Young modulus $E(\mathrm{GPa})$; Poisson's ratio $v$; Friction angle $\phi(\mathrm{deg})$; Dilation angle $\psi(\mathrm{deg})$; Logarithmic Plastic Bulk Modulus $\lambda$, defined as

$$
\frac{d e}{d(\ln p)}=-\lambda
$$

where $e$ is the voids ratio and $p$ is the effective pressure stress; the Initial Yield Surface Size is $p_{y i}(\mathrm{kPa})$. These parameters were the input data for the Abaqus program code [1], and they were determined by well-known and standardized procedures performed by triaxial test apparatus as already used by numerous authors including [5], [17], [18], [20], [23], and precisely:

Poisson's ratio $v$ was obtained from the initial stages of 1D unloading with lateral stress measurement in a triaxial apparatus. The direct estimation of dilation angle $\psi$ was obtained from the results of volumetric strain versus deviatoric strain in a constant $p$ triaxial test. $p_{y i}$ was the value of the mean effective stress at the initial yield point for an isotropic stress state and was numerically equal to the size of the initial yield surface associated with the initial soil structure. Logarithmic Plastic Bulk Modulus $\lambda$ was determined from the hydrostatic compression experimental data by plotting the logarithm of pressure versus void ratio. Furthermore, by using the statistical program code SYSTAT, mean values and Standard Deviations for the aforementioned parameters were evaluated and reported in Table 1.

We used a soil shearometer unit to perform soil shear tests (Eijkelkamp Agrisearch Equipment, Netherlands). Its principle was rather simple: an axle with vanes (or fins) connected to it was placed vertically in the soil and we then applied a clockwise rotation to that to make sure that failure could only develop within 5-10 s. Required moment was measured at soil breakpoint and we were able to use it to calculate shear stress at the measuring point. This full field shearometer then constituted a standard set for measurement of shear strength stress up to $200 \mathrm{kPa}$ to a depth of $3 \mathrm{~m} \mathrm{[4],} \mathrm{[12],} \mathrm{[26].} \mathrm{The} \mathrm{field} \mathrm{inspection} \mathrm{vane}$ tester was used to determine the maximum shearing moment to be applied to a considered soil. By using special equipment, we could automate the detecting phase. Complete soil shearometer unit construction derived from the following main sub-assemblies: a main frame supporting a moving carriage sub-assembly which in turn supported the shearometer and the gear-type driving mechanisms supporting the moving carriages traverse movements. The complete unit was $1030 \mathrm{~mm}$ long, $200 \mathrm{~mm}$ wide and $1300 \mathrm{~mm}$ high. The shearometer unit provided "in situ" measurement of the shear stress as well as recording by a data acquisition system. The shearometer was able to operate in a measurement range from 5 to $80 \mathrm{Nm}$ at $0.1 \mathrm{Nm}$ resolution and this equipment allowed us to detect agricultural soil shear stress for every considered soil type. During the experimental tests, for each type of examined soil, we considered 4 sample points, vertexes of a $5 \mathrm{~m}$ by $5 \mathrm{~m}$ size grid, for soil shear stress measurement data collection. We were therefore able to measure and record the soil shear stress in 4 soil sampling points throughout the field tests. Each soil sampling measurement set took less than 15 min to be acquired. The equipment used allowed us to determine the shear stress $\tau_{R}$, by the acting moment value $M_{R}$, causing considered soil cylinder breaking. The equipment used also allowed us to detect the $\tau_{R}$ values at different normal pressure values $p$. We utilised three weights in order to simulate a normal pressure $p$ of 0 , $14.3,28.6,43.0 \mathrm{kPa}$. and, in this way, we were able to determine the corresponding $\tau_{R}$ values. Furthermore, the shearometer unit was disconnected from the mainframe when the weights (disks with a buttonhole) were applied to it so that the load was only applied to the shearometer unit. Our test device was made of two

\begin{tabular}{|c|c|c|c|c|c|}
\hline Soil type & $\mathrm{A}$ & $\mathrm{B}$ & $\mathrm{C}$ & $\mathrm{D}$ & $\mathrm{E}$ \\
\hline $\begin{array}{c}* \text { Clay } \\
(\%)\end{array}$ & $25 \pm 13$ & $35 \pm 11$ & $55 \pm 15$ & $52 \pm 15$ & $35 \pm 11$ \\
\hline $\begin{array}{c}* \text { Sand } \\
(\%)\end{array}$ & $63 \pm 17$ & $42 \pm 13$ & $19 \pm 9$ & $35 \pm 11$ & $48 \pm 14$ \\
\hline $\begin{array}{c}* \text { Silt } \\
(\%)\end{array}$ & $12 \pm 9$ & $23 \pm 13$ & $26 \pm 14$ & $13 \pm 9$ & $17 \pm 12$ \\
\hline $\begin{array}{c}* \mathrm{APLU} \\
\left(\% \mathrm{H}_{2} \mathrm{O}\right)\end{array}$ & $16.6 \pm 10$ & $28 \pm 13$ & $352 \pm 11$ & $40 \pm 12$ & $325 \pm 11$ \\
\hline $\begin{array}{c}* \mathrm{APLL} \\
\left(\% \mathrm{H}_{2} \mathrm{O}\right)\end{array}$ & $10 \pm 9$ & $228 \pm 13$ & $164 \pm 10$ & $189 \pm 12$ & $232 \pm 17$ \\
\hline $\begin{array}{c}m \\
(\%)\end{array}$ & $15 \pm 10$ & $21 \pm 12$ & $18 \pm 11$ & $21 \pm 12$ & $13 \pm 10$ \\
\hline $\begin{array}{c}* \mathrm{E} \\
(\mathrm{GPa}) 10^{3}\end{array}$ & $30 \pm 13$ & $41 \pm 15$ & $70 \pm 17$ & $67 \pm 16$ & $55 \pm 10$ \\
\hline$* v$ & $030 \pm 0.01$ & $025 \pm 0.01$ & $033 \pm 0.01$ & $029 \pm 0.01$ & $027 \pm 0.01$ \\
\hline $\begin{array}{c}* \phi \\
(\mathrm{deg})\end{array}$ & $57 \pm 15$ & $60 \pm 19$ & $40 \pm 15$ & $53 \pm 17$ & $49 \pm 16$ \\
\hline $\begin{array}{c}* \psi \\
(\mathrm{deg})\end{array}$ & $34 \pm 11$ & $27 \pm 10$ & $11 \pm 9$ & $26 \pm 10$ & $28 \pm 11$ \\
\hline$* \lambda$ & $0.025 \pm 0.01$ & $0.035 \pm 0.01$ & $0.193 \pm 0.01$ & $0.15 \pm 0.09$ & $0.105 \pm 0.08$ \\
\hline $\begin{array}{c}* p_{y i} \\
(\mathrm{kPa})\end{array}$ & $300 \pm 11$ & $350 \pm 13$ & $265 \pm 10$ & $320 \pm 12$ & $400 \pm 16$ \\
\hline
\end{tabular}

*Means values of four tests \pm S.D.

TABLE 1 - Soil parameters values used in the numerical simulations. 
iron blades that crossed in the middle and orthogonally. We considered the soil shear box device's metallic components as rigid parts. The cylindrical sample of soil was $60 \mathrm{~mm}$ wide and $120 \mathrm{~mm}$ high. We also considered the soil's cylindrical wedge included between two adjacent blades and several FEM models of shear strength tests were developed for shear test simulations. For the considered tests, the meshing was done using elements with mean corner dimensions of 20 $\mathrm{mm}$ since we noticed that narrower mesh did not improve data results. The model as a whole was composed of 16,640 elements and we considered a parabolic element type. Boundary conditions for the numerical simulation considered were pressure $p$ applied to upper surface's 289 nodes whereas a tangential pressure was applied to the lateral surface's 976 nodes. Its lower surface was integral with the surrounding soil and rotation was clockwise. Break-up torque moment values $M_{R}$ detected during experimental tests were applied during the numerical simulation and we could evaluate the corresponding shear stress $\tau_{R}$ maximum numerical values using three different material models for each considered soil, the MohrCoulomb, Drucker-Prager and Cam-Clay models.

\section{Results and discussion}

For every type of soil considered, we performed 4 soil shear stress tests and $M_{R}$ and $\tau_{R}$ were determined. In Fig. 1, shear stress mean values $\tau_{R}$ detected during

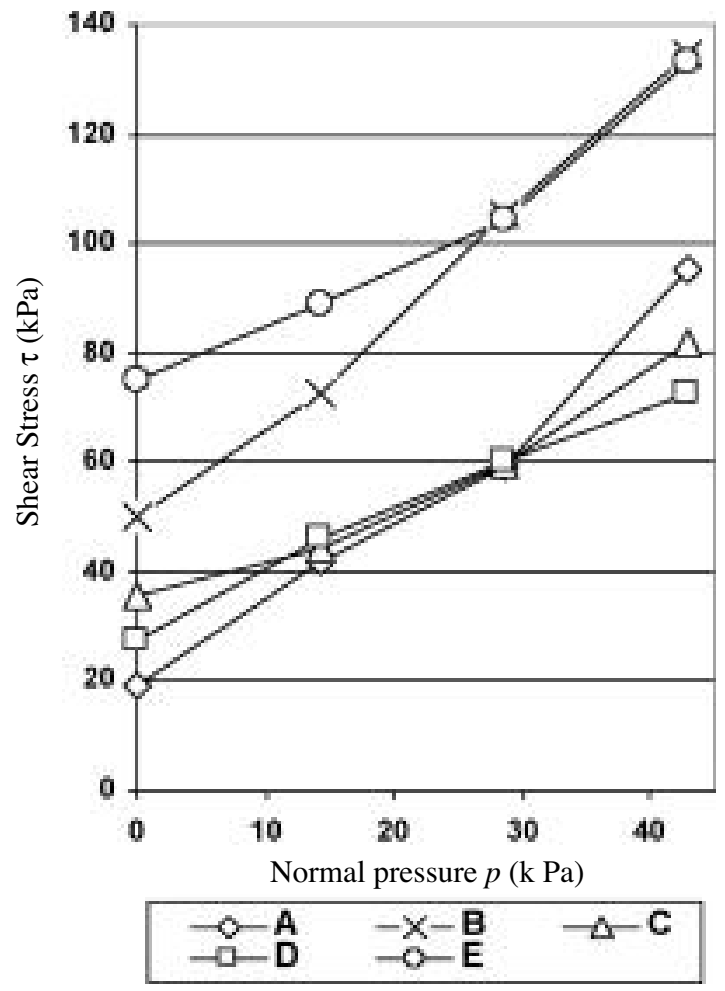

Fig. 1 - Shear stress mean values $\left(\tau_{R}\right)$ - normal pressure $(p)$ diagram for considered soils $(A, B, C, D, E)$ with normal pressure $p=0$, $14.3 ; 28.6 ; 43.0 \mathrm{kPa}$. the experimental tests were reported at normal pressure $p=0,14.3 ; 28.6 ; 43.0 \mathrm{kPa}$. Furthermore, we observed that the maximum difference between maximum and minimum values detected during the tests was never greater than $4 \%$ for every set of soil shear tests considered at the same normal pressure value.

The shear test simulations were performed using the FEM discretized model. They were performed using a PC with a $3 \mathrm{GHz}$ Intel processor and $1024 \mathrm{Mb}$ RAM and the solutions were obtained in about $15 \mathrm{~min}$. The data results obtained by numerical simulations were compared with the obtained experimental data and reported in Table 2. In this table we reported maximum shear stress values $\tau_{\text {Rexp }}$ derived from experimental tests and maximum shear stress values $\tau_{\text {Rnum }}$ obtained by numerical simulations performed using Mohr Coulomb, Drucker Prager and Cam Clay models. We defined error $\varepsilon$ as :

$$
\varepsilon=\left(1-\frac{T_{\text {Resp }}}{t_{\text {Ran }}}\right) \cdot 100
$$

and also reported it in Table 2.

By examining data from each considered set of tests, we noticed different $\tau$ distribution for the three models considered:

In the Mohr Coulomb model, we noticed a more uniform $\tau_{R}$ maximum value distribution involving the whole lateral surface considered (fig. 2a) since, according to the material model theory considered, failure is controlled only by the maximum shear values $\tau_{R}$.

In the Drucker Prager model, we noticed on the other hand that the $\tau_{R}$ maximum value zone covered a smaller part of the lateral surface (fig. $2 \mathrm{~b}$ ) since, according to material model theory considered, the yield surface includes two segments: a shear failure surface and a "cap" which intersects the pressure stress axis. For this reason, there is a small area with $\tau_{R}$ maximum values.

In the Cam-Clay model, the $\tau_{R}$ maximum value zone involved a very small part of the lateral surface considered. We also noticed clear swelling of the considered soil (fig. 2c) since, according to the material model theory considered, it takes the soil porosity, the fact that the yield function depends on the three stress invariants and the fact that the strain hardening theory changes the size of the yield surface according to the inelastic volumetric strain into account.

Furthermore, we must point out that, on the basis of the data results obtained for the considered soils, we experienced more difficulty performing the shear test numerical simulation when using the Mohr Coulomb material model. As can be seen in Table 2, $\tau_{R}$ shear stress values in every considered load condition, differ considerably from experimental values. As we can see from the data results obtained with the Mohr Coulomb model, $\tau_{R}$ shear stress values differed significantly from those obtained with experimental tests and the error $\varepsilon$ between the values obtained by experimental tests and the Mohr Coulomb model in- 
creased along with the clay content (maximum error about $34 \%$ ).

As a matter of fact, this type of material model was turned out to be inadequate for the soil types considered in our tests. It is important to underline that we could obtain $\tau_{R}$ shear stress values that were rather similar to the experimental ones for A and B soils (maximum error differences of approximately -4.1 $\%$ ) by using the Drucker Prager material model whereas when we took C, D and E soils into account, the maximum error differences were about $12 \%$ (for soil with a clay content of approximately 25-35\%) with a moisture content of approximately 13-21\%. Indeed such material model was inadequate to simulate soil types C, D, E.
In addition, we were able to obtain $\tau_{R}$ shear stress values similar to the experimental ones for $\mathrm{C}, \mathrm{D}, \mathrm{E}$ soils using the Cam-Clay model (maximum error differences approximately $+5 \%$ ), whereas in A and B soils, error differences were higher (maximum error differences approximately $-11 \%$ ). Indeed such material model was inadequate to simulate soil types A,B.

As can be seen from the aforementioned data for the considered soils, we can affirm that soils with a higher clay content (approx. 35-55\%), like those considered in these cases, are properly modelled by CamClay material models whereas soils with a clay content of about 25-35\% are better modelled by Drucker Prager material models.

\begin{tabular}{|c|c|c|c|c|c|}
\hline $\begin{array}{c}\mathrm{p} \\
\text { Normal } \\
\text { load } \\
\mathrm{kPa} \\
\end{array}$ & $\begin{array}{c}\mathrm{M} \\
\text { Moment daN } \\
\mathrm{m}\end{array}$ & $\begin{array}{c}* \tau_{\mathrm{Rexp}} \\
\text { Shear stress } \\
\mathrm{kPa} \\
\text { experimental }\end{array}$ & $\begin{array}{c}\tau_{\text {Rnum }} \\
\text { Shear stress } \\
\mathrm{kPa} \\
\text { Mohr Coulomb } \\
\end{array}$ & $\begin{array}{c}\tau_{\mathrm{Rnum}} \\
\text { Shear stress } \\
\mathrm{kPa} \\
\text { Drucker_Prager }\end{array}$ & $\begin{array}{c}\tau_{\mathrm{Rnum}} \\
\text { Shear stress } \\
\mathrm{kPa} \\
\text { Cam-Clay } \\
\end{array}$ \\
\hline \multicolumn{5}{|c|}{ Soil A } & \\
\hline 0 & 1.05 & 19.1 & $22.01(+13 \%)$ & $18.33(-4.2 \%)$ & $17.20(-11 \%)$ \\
\hline 14.3 & 2.28 & 41.6 & $38.44(-8 \%)$ & $43.10(+3.5 \%)$ & $45.60(+8.7 \%)$ \\
\hline 28.6 & 3.24 & 59.3 & $53.5(-0.8 \%)$ & $61.30(+3.3 \%)$ & $65.10(+8.9 \%)$ \\
\hline 43.0 & 5.20 & 95.3 & $86.77(9.8 \%)$ & $99.01(+3.7 \%)$ & $104.8(+9.1 \%)$ \\
\hline \multicolumn{5}{|c|}{ Soil B } & \\
\hline 0 & 2.75 & 50.3 & $56.33(+11 \%)$ & $48.28(-4.1 \%)$ & $45.30(-11 \%)$ \\
\hline 14.3 & 3.85 & 72.8 & $66.52(9.4 \%)$ & $75.70(+3.8 \%)$ & $80.10(+9.1 \%)$ \\
\hline 28.6 & 5.75 & 105.3 & $95.70(-10 \%)$ & $109.10(+3.5 \%)$ & $115.77(+9 \%)$ \\
\hline 43.0 & 7.35 & 134.5 & $122.70(9.6 \%)$ & $138.90(+3.16 \%)$ & $147.85(+9 \%)$ \\
\hline \multicolumn{5}{|c|}{ Soil C } & \\
\hline 0 & 1.93 & 35.4 & $26.32(-34 \%)$ & $31.96(-10.7 \%)$ & $33.98(-4.1 \%)$ \\
\hline 14.3 & 2.40 & 44.1 & $33.21(-33 \%)$ & $48.55(+9 \%)$ & $46.56(+5.2 \%)$ \\
\hline 28.6 & 3.26 & 59.8 & $45.84(-30 \%)$ & $65.80(+9.1 \%)$ & $63.19(+5.3 \%)$ \\
\hline 43.0 & 4.46 & 81.6 & $63.28(-29 \%)$ & $89.76(+9 \%)$ & $85.86(+4.9 \%)$ \\
\hline \multicolumn{5}{|c|}{ Soil D } & \\
\hline 0 & 1.49 & 27.3 & $20.84(-31 \%)$ & $24.61(-10.9 \%)$ & $26.10(-4.5 \%)$ \\
\hline 14.3 & 2.53 & 46.4 & $36.12(-28 \%)$ & $51.05(+9.1 \%)$ & $48.80(+4.9 \%)$ \\
\hline 28.6 & 3.29 & 60.3 & $47.24(-27.6 \%)$ & $66.38(+9.1 \%)$ & $63.00(+4.3 \%)$ \\
\hline 43.0 & 3.97 & 72.8 & $57.74(-26 \%)$ & $80.01(+9 \%)$ & $76.05(+4.2 \%)$ \\
\hline \multicolumn{5}{|c|}{ Soil E } & \\
\hline 0 & 4.11 & 75.2 & $58.16(-29 \%)$ & $67.20(-12 \%)$ & $72.20(-4.1 \%)$ \\
\hline 14.3 & 4.86 & 89.0 & $68.20(-30 \%)$ & $97.98(+9.1 \%)$ & $94.20(+5 \%)$ \\
\hline 28.6 & 5.71 & 104.4 & $80.52(-29.6 \%)$ & $114.96(+9.2 \%)$ & $107.20(+2.6 \%)$ \\
\hline 43.0 & 7.28 & 133.4 & $103.72(+28 \%)$ & $146.94(+9.2 \%)$ & $137.80(+3.1 \%)$ \\
\hline
\end{tabular}

TABLE $\quad 2-\tau_{\mathrm{R}}$ Shear stress values and Moment acting for the considered soils with load pressure $\mathrm{p}=0,14.3 ; 28.6 ; 43.0 \mathrm{kPa}$ (error $\varepsilon$ is shown in parenthesis) 


\section{Conclusions}

The outcomes of our research demonstrate how several numerical simulations must be performed by examining different material models among those already available in the literature in order to determine a material model that is suitable for simulating the mechanical behaviour of a considered soil. Therefore, soil characteristic parameters must be known beforehand and can be easily derived from hydrostatic compression and triaxial tests.

The data results obtained highlighted the fact that the Mohr Coulomb material model was rather inadequate for simulating the considered soils. The Drucker Prager material model, on the other hand, appears to be more suitable for simulating the mechanical behaviour of soils with a clay content of $25-35 \%$ and moisture content of $15-21 \%$ (typology A and B considered) whereas for soils with a higher clay content (35-55\%) and moisture content (13-21\%), the Cam-Clay material model turns out to be the best for simulating the mechanical behaviour of the real soil considered (typology C, D, E). Nonetheless, it is important to stress that a moisture content that differs a great deal from considered soil values could invalidate our claim since the mechanical behaviour of the soil strongly depends on the moisture content.

\section{References}

[1] Abaqus Analysis User's Manual v 6.5.

[2] Bailey A.C., Johnson C.E., Schafer R.L., Hydrostatic Compaction of Agricultural Soils. Trans. ASAE. (1984) 952-955.

[3] Bishop A.W., Henkel, D.J., The Measurement of Soil Properties in the Triaxial cell. (1969), Edward Arnold, London.

[4] Boon N.E., Yahya A., Kheiralla A.F., Wee B.S., GEW S.K., A tractor mounted, automated soil penetrometer-shearometer unit for mapping soil mechanical properties. Biosystems Engineering. (2005) 90, (4), 381-396.

[5] BORJ A.R., Cam-Clay plasticity, Part II, Implicit integration of constitutive equations based on a non linear elastic stress predictor. Comp. Meth. Appl. Mech. Engng. (1991), 88, 225-240.

[6] BRITTO A.M., GunN M.J., Critical State Soil Mechanics via Finite Elements. (1987), Ellis Horwood, Chichester.

[7] CARTER J.P., Predictions of the non-homogeneous behaviour of clay in the triaxial test. Géotechnique, (1982),32, (1), 55-58.

[8] De Borst R., Groen A.E., Computational Strategies for Standard Soil Plasticity Models. In: Modelling in Geomechanics. Edited by Zaman, J. Booker and G. Gioda. (2000) John Wiley \& Sons. Ltd.

[9] EsCARIO V., SÀEZ J., The shear strength of partly saturated soils. Géotechnique (1986), 36-453,456.

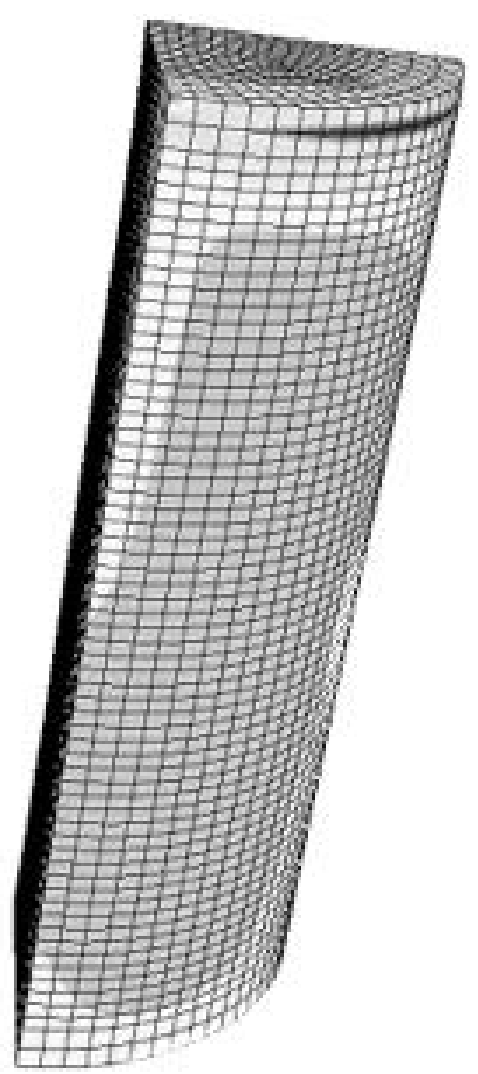

a)

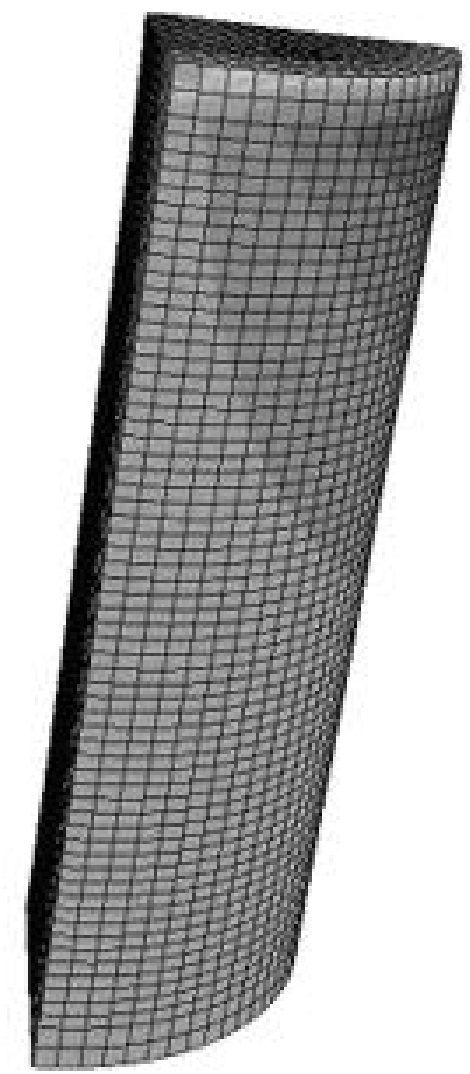

b)

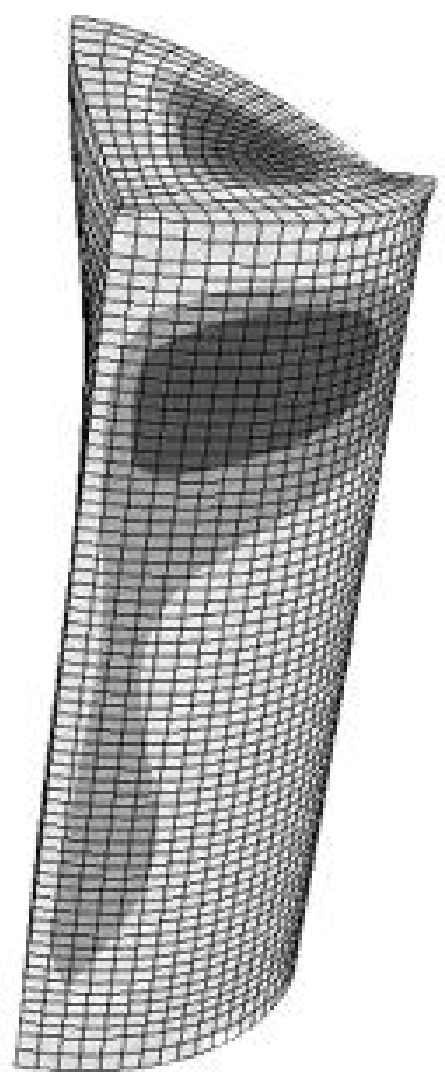

c)

Fig. 2 - Shear test simulation outcomes by: a) Mohr Coulomb material model; b) Drucker- Prager material model; c) Cam-Clay material model. Very dark grey zones have high $\tau_{R}$ values. 
[10] Formato A., Messa a punto di un'apparecchiatura per lo studio delle caratteristiche meccaniche dei terreni insaturi. Riv. di Ing. Agr. (2001) 3, 170-177.

[11] Formato A., Simplified triaxial apparatus to test agricultural soils. Soil Tillage \& Research. (2005), 81,(1), 121-129.

[12] Formato A., Faugno S., Paolillo G., La valutazione della resistenza dei terreni agrari per l'agricoltura di precisione. In Atti del VIII Convegno Nazionale di Ingegneria Agraria: L'Ingegneria Agraria per lo Sviluppo Sostenibile dell'area mediterranea Catania27-20 giugno 2005.

[13] Fredlund D.G., Morgenstern N.R., Widger R.A., Shear strength of unsaturated soils. Can. Geotech. J. (1978), 15-313,321.

[14] Golob T.B., Development of a terrain strength measuring system. Journal of Terramechanics, (1981) 18(2),109-118.

[15] Grisso R.D., Johnson C.E., Bailey C.A., Nichols T.A., Influences of soil sample geometry on hydrostatic compaction. Trans. ASAE.(1984), 27,(6), 16501653.

[16] Khallili N., KhabBaz, M.H., A unique relationship for the determination of the shear strength of unsaturated soils. Geotechnique. (1998) 48;681-687.

[17] KIRBY J.M., Measurements of the yield surfaces and critical state of some unsaturated agricultural soils, Journal of Soil Science. (1989) 40, 167-182.

[18] LiU M.D., CARTER J.P., A structured Cam Clay model. Can. Geotech J.. (2002) 39, 1313-1332.

[19] RAPER R.L., ERBACH D.C., Prediction of soil stresses using the finite element method. Transaction of the ASAE.(1990) 33, 725-730.

[20] Spoor G., Godwin R.J., Deformation and shear strength characteristics of some clay soils at different moisture contents. Journal of Soil Science, (1979) 30, 483-498.

[21] STAFFORD J.V., TANNER D.W., Field measurement of soil shear strength and a new design of field shear meter. $9^{\text {th }}$ Conference of the International Soil Tillage Research Organisation (ISTRO) 1982, 656-661.

[22] Tine' G., Formato A., Note sulla meccanica del suolo agrario in tempera . - Ed. Chiarlizia (1996) 1-14

[23] VAN EEKELEN H.A.M., Isotropic yield surfaces in three dimensions for use in soil mechanics. Int. J. Num. An. Meth. Geom. (1980) 4, 89-101.

[24] Yunming Y., Yu H. S., Numerical simulations of simple shear with non-coaxial soil models. Int. J. Numer. Anal. Meth. Geomech., (2006) 30-1,19.
[25] Wulfsohn D., AdAms B.A., Fredlund D. G., Triaxial testing of unsatured agricultural soils. J. Agric. Eng. Res.(1998) 69, 317-330.

[26] Zimbone S.M., Vickers A., Morgan R.P:, Vella P., Field investigations of different techniques for measuring surface soil strength. Soil Technology. (1996) 9, 101-111.

\section{SUMMARY}

In this work a numerical simulation of agricultural soil shear stress tests was performed through soil shear strength data detected by a soil shearometer. We used a soil shearometer available on the market to measure soil shear stress and constructed special equipment that enabled automated detection of soil shear stress. It was connected to an acquisition data system that displayed and recorded soil shear stress during the full field tests. A soil shearometer unit was used to the in situ measurements of soil shear stress in full field conditions for different types of soils located on the right side of the Sele river, at a distance of about $1 \mathrm{~km}$ from each other, along the perpendicular to the Sele river in the direction of the sea. Full field tests using the shearometer unit were performed alongside considered soil characteristic parameter data collection. These parameter values derived from hydrostatic compression and triaxial tests performed on considered soil samples and repeated 4 times and we noticed that the difference between the maximum and minimum values detected for every set of performed tests never exceeded $4 \%$. Full field shear tests were simulated by the Abaqus program code considering three different material models of soils normally used in the literature, the Mohr-Coulomb, Drucker-Prager and Cam-Clay models. We then compared all data outcomes obtained by numerical simulations with those from the experimental tests. We also discussed any further simulation data results obtained with different material models and selected the best material model for each considered soil to be used in tyre/soil contact simulation or in soil compaction studies.

Key words: Shearometer, Shear stress test, Soil mechanics. 